Pendas : Jurnal IImiah Pendidikan Dasar,

ISSN Cetak : 2477-2143 ISSN Online : 2548-6950

Volume II Nomor 2, Desember 2017

\title{
PENGARUH MODEL PEMBELAJARAN BAMBOO DANCING (TARI BAMBU) TERHADAP HASIL BELAJAR IPS SISWA SDN 1 CIPEDES
}

\author{
Nana Sutarna ${ }^{1}$ \\ 1Program Studi PGSD STKIP Muhammadiyah Kuningan \\ ${ }^{1}$ nana@upmk.ac.id \\ Dian Kusdiana ${ }^{2}$ \\ 2Program Studi PGSD STKIP Muhammadiyah Kuningan \\ 2dkusdiana73@gmail.com
}

\begin{abstract}
This research is based on the writer's anxiety about student learning outcomes that are still under KKM. The purpose of this study to determine the effect of learning models bamboo dancing (bamboo dance) on the results of learning IPS class V SDN 1 Cipedes. Learning model of bamboo dancing (bamboo dance) and learning result are the variables studied. This research uses experimental method with quasi experimental design nonequevalent control group design that is two classes of experimental research (treated) and control (without treatment). After doing the calculations, the results of this study indicate an increase in learning outcomes IPS class $V$ students by using learning models of bamboo dancing (bamboo dance), namely; (1) before being treated the average score of students' learning achievement of 53.49; (2) after being treated the mean value of student learning result of IPS is 82,06 and (3) the mean of posttest of experiment class is 82,06 and the mean of posttest of control class is 71,69. From the calculation result, the average value of the experimental class is better than the control class. So it can be concluded that the learning model of bamboo dancing (bamboo dance) improves the learning outcomes of IPS students of SDN 1 Cipedes.
\end{abstract}

Keyword: Bamboo dancing model (bamboo dance), learning result

\section{ABSTRACT}

Penelitian ini didasari atas kegelisahan penulis terhadap hasil belajar siswa yang masih dibawah KKM. Tujuan penelitian ini untuk mengetahui pengaruh model pembelajaran bamboo dancing (tari bambu) terhadap hasil belajar IPS siswa kelas V SDN 1 Cipedes. Model pembelajaran bamboo dancing (tari bambu) dan hasil belajar merupakan variabel yang diteliti. Penelitian ini menggunakan metode eksperimen dengan desain quasi eksperimental nonequevalent control group design yaitu dua kelas penelitian eksperimen (diberi perlakuan) dan kontrol (tanpa perlakuan). Setelah melakukan perhitungan, hasil penelitian ini menunjukkan adanya peningkatan hasil belajar IPS siswa kelas $\mathrm{V}$ dengan menggunakan model pembelajaran bamboo dancing (tari bambu), yaitu; (1) sebelum diberi perlakuan nilai rata-rata hasil belajar IPS siswa sebesar 53,49; (2) setelah diberi perlakuan nilai rata-rata hasil belajar IPS siswa sebesar 82,06 dan (3) nilai rata-rata posttest kelas eksperimen sebesar 82,06 dan nilai rata-rata posttest kelas kontrol sebesar 71,69 . Dari hasil perhitungan tersebut nilai rata-rata kelas eksperimen lebih baik dari kelas kontrol. Maka dapat disimpulkan bahwa model pembelajaran bamboo dancing (tari bambu) meningkatkan hasil belajar IPS siswa SDN 1 Cipedes. 


\section{A. Pendahuluan}

Pada dasarnya setiap siswa mempunyai karakter yang unik dan berbeda satu sama lainnya. Karakter yang dibawa siswa dari keluarga, cenderung bervarasi. Hal ini dipengaruhi oleh pendidikan keluarga (informal) dan lingkungan masyarakat setempat. Ketika siswa masuk pada jenjang Sekolah Dasar, pendidikan terhadap siswa merupakan tanggung jawab seorang guru. Proses pendidikan di Sekolah Dasar berlangsung selama enam tahun dan paling lama diantara jenjang pendidikan lainnya. Hal ini dikarenakan, siswa Sekolah Dasar perlu bimbingan secara mendalam terhadap intelektual maupun spiritual agar dapat mendasari proses pendidikan pada tahap berikutnya.

Pada proses pembelajaran siswa harus menguasai pengetahuan, sikap, dan keterampilan berdasarkan bimbingan guru selama proses pendidikan berlangsung. Setelah berakhirnya pendidikan secara formal, maka diharapkan siswa dapat membawa manfaat bagi orang tua, masyarakat, bangsa, dan negara. Realitas nya pendidikan tidak dapat berlangsung tanpa adanya guru, maka dari itu peran guru begitu penting bagi tumbuh nya generasi bangsa yang cerdas, berprestasi, dan berakhlak mulia.

Tugas guru sangat multifungsi selain mendidik dan membimbing, mengajar adalah hal yang wajib dilakukan seorang guru terutama pada siswa Sekolah Dasar (SD). Karena pada jenjang ini pertama kali siswa

menerima

materi

pembelajaran. Materi pembelajaran yaitu bagian yang tidak terpisahkan dari mata pelajaran tertentu, salah satunya adalah IImu Pengetahuan Sosial (IPS).

IImu Pengetahuan Sosial adalah ilmu yang mempelajari berbagai gejala sosial yang erat kaitannya dengan kehidupan manusia. Penanaman konsep materi pembelajaran IPS dalam pendidikan formal sudah dikenalkan kepada siswa sejak jenjang pendidikan Sekolah Dasar. "Istilah IPS disekolah dasar merupakan nama mata pelajaran yang berdiri sendiri sebagai integrasi dari sejumlah konsep disiplin ilmu sosial, humaniora, sains bahkan berbagai isu dan masalah sosial kehidupan" (Sapriya, 2009: 20). Dari penjelasan tersebut bahwa IPS dapat diturunkan menjadi beberapa disiplin ilmu sosial, seperti sejarah, geografi, ekonomi, antropologi, sosiologi bahkan ilmu sosial lainya.

Pada dasarnya siswa Sekolah Dasar lebih menyukai sesuatu yang baru dan belum pernah dialami sebelumnya. Maka dari itu, guru harus mengimplementasikan sistem pembelajaran yang baru untuk menciptakan pembelajaran yang aktif, inovatif, kreatif, efektif, serta menyenangkan bagi siswa. Hal ini bertujuan untuk meningkatkan hasil belajar siswa pada mata pelajaran IPS.

Namun berdasarkan pengamatan di kelas $\mathrm{V}$ pada mata pelajaran IPS realitanya guru belum menggunakan model pembelajaran 
yang relevan dan pembelajaran berpusat pada guru (teacher oriented). Hal tersebut berdampak pada rendahnya hasil belajar siswa, perlu adanya solusi untuk memecahkan masalah tersebut.

Asumsi dasar bahwa untuk meningkatkan hasil belajar siswa kelas $\mathrm{V}$ pada mata pelajaran IPS yaitu dengan cara memberikan trobosan baru berupa model pembelajaran bamboo dancing (tari bambu). Model pembelajaran bamboo dancing (tari bambu) merupakan pengimplementasian pembelajaran dengan prosedur yang sistematis dengan cara siswa saling bertukar informasi satu sama lain sesuai dengan materi pembelajaran. Diterapkannya model pembelajaran bamboo dancing (tari bambu) pada pembelajaran IImu Pengetahuan Sosial (IPS), karena memiliki keunggulan dibandingkan dengan metode ceramah. Huda (2011: 147), menjelaskan bahwa model pembelajaran bamboo dancing (tari bambu) memiliki keunggulan yaitu adanya struktural yang jelas, memungkinkan siswa untuk saling bertukar informasi dengan singkat dan teratur, memberi kesempatan kepada siswa untuk mengolah informasi dan meningkatkan keterampilan komunikasi mereka dan dapat diterapkan untuk semua kelas. Maka dari itu, dengan mengolah informasi dan keterampilan komunikasi tersebut siswa dapat memahami materi pembelajaran dan dapat meningkatkan hasil belajarnya.

\section{B. Landasan Teori}

\section{Hakikat IPS di Sekolah Dasar}

Pada hakikatnya IImu

Pengetahuan Sosial (IPS) merupakan ilmu pengetahuan yang memiliki berbagai disiplin ilmu sosial yang erat kaitannya dengan kehidupan manusia. Selain itu, IImu Pengetahuan Sosial (IPS) adalah salah satu mata pelajaran yang diterapkan pada jenjang sekolah dasar.

Susanto (2012: 138), menjelaskan bahwa hakikat IPS di sekolah dasar memberikan pengetahuan dasar dan keterampilan sebagai media pelatihan bagi siswa sebagai warga negara sedini mungkin. Karena, pendidikan IPS tidak hanya memberi ilmu pengetahuan semata, tetapi harus berorientasi pada pengembangan keterampilan berpikir kritis, sikap, dan kecakapan-kecakapan dasar siswa yang berpijak pada kenyataan kehidupan sosial kemasyarakatan sehari-hari dan memenuhi kebutuhan bagi kehidupan siswa di masyarakat. Lebih lanjut Susanto mengatakan hakikat pendidikan IPS di Sekolah Dasar merupakan bidang studi yang mempelajari manusia dalam semua aspek kehidupan dan interaksinya dalam masyarakat.

$\begin{array}{cr}\text { Ilmu } & \text { Pengetahuan Sosial } \\ \text { hendaknya } & \text { dikembangkan }\end{array}$
berdasarkan kondisi sosial budaya yang ada di lingkungan siswa, hal ini menunjukkan bahwa siswa akan menjadi warga negara yang baik dan mampu menelaah dan memahami kehidupan sosial di lingkungan tempat hidupnya. Selain itu IImu 
Pengetahuan Sosial mengkaji berbagai aspek kehidupan manusia dengan lingkungannya sehingga siswa dapat mengetahui akan pentingnya mempelajari IPS.

Pendidikan IImu Pengetahuan Sosial merupakan salah satu mata pelajaran yang dapat memberikan wawasan pengetahuan yang luas mengenai masyarakat lokal maupun global sehingga mampu hidup bersama-sama dengan masyarakat. Untuk mencapai tujuan tersebut, Sekolah Dasar (SD) sebagai lembaga formal dapat mengembangkan dan melatih potensi diri siswa yang mampu melahirkan manusia yang handal, baik dalam bidang akademik maupun dalam aspek moralnya.

\section{Model pembelajaran bamboo bancing}

Huda (2011: 147), menjelaskan bahwa tari bambu merupakan pengembangan dan modifikasi dari teknik lingkaran kecil lingkaran besar. Selain itu, dinamakan tari bambu karena siswa diibaratkan seperti bambu yang berjajar serta saling berhadapan dan saling berbagi informasi pada waktu yang bersamaan dengan model yang mirip seperti dua potong bambu yang digunakan dalam tari bambu Filipina yang juga populer di beberapa daerah di Indonesia.

Model pembelajaran bamboo dancing bertujuan agar siswa memiliki pengetahuan dan keterampilan berbicara dalam menyampaikan informasi berupa materi pembelajaran kepada temannya secara bergantian dengan batas waktu yang ditentukan (Shoimin, 2014). Dengan hal tersebut, siswa dapat memahami materi pembelajaran dan dapat meningkatkan hasil belajar pada mata pelajaran IImu Pengetahuan Sosial.

Zainal (2013: 35) langkahlangkah model pembelajaran bamboo dancing yaitu sebagai berikut:

1) Separuh jumlah siswa di kelas atau seperempatnya jika jumlah siswa terlalu banyak berdiri berjajar. Jika ada cukup ruang, siswa bisa berjajar di depan kelas. Kemungkinan lain adalah siswa berjajar di sela-sela deretan bangku.

2) Cara yang kedua ini akan memudahkan pembentukan kelompok karena diperlukan waktu yang relatif singkat.

3) Separuh kelas lainnya berjajar dan menghadap jajaran yang pertama.

4) Dua siswa yang berpasangan dari kedua jajaran pindah ke ujung lainnya di jajarannya. Jajaran ini kemudian bergeser. Dengan cara ini masing-masing siswa mendapat pasangan yang baru untuk berbagi. Pergeseran bisa dilakukan terus sesuai dengan kebutuhan.

Model ini memiliki beberapa kelebihan diantaranya: (1) siswa dapat bertukar pengalaman dan pengetahuan dengan sesamanya dalam proses pembelajaran; (2) Meningkatkan kecerdasan sosial dalam hal kerja sama di antara siswa; dan (3) Meningkatkan toleransi antara sesama siswa. 
Selain kelebihan, ada beberapa kekurangan dalam model bamboo dancing diantaranya: (1) Kelompok belajarnya terlalu gemuk sehingga menyulitkan proses belajar mengajar; (2) Siswa lebih banyak bermain dari pada belajar; dan (3) Memerlukan periode waktu yang cukup panjang.

\section{Hasil Belajar}

Hasil belajar merupakan sesuatu yang diperoleh siswa dalam bentuk kognitif, afektif, maupun psikomotorik sebagai dampak dari kegiatan pembelajaran. Nawawi (dalam Susanto, 2012: 5), yang menyatakan bahwa hasil belajar dapat diartikan sebagai tingkat keberhasilan siswa dalam mempelajari materi pelajaran di sekolah yang dinyatakan dalam skor yang diperoleh dari hasil tes mengenal sejumlah materi pelajaran tertentu.

Hasil belajar siswa dipengaruhi oleh dua faktor yaitu internal dan eksternal. Faktor internal yaitu segala sesuatu yang berasal dari dalam diri siswa tanpa adanya pengaruh dari luar. Siswa yang menentukan kualitas belajarnya serta hasil belajar yang didapatkan. Sedangkan faktor eksternal merupakan segala sesuatu yang berasal dari luar diri siswa (adanya pengaruh orang lain) yang mempengaruhi kualitas belajar serta hasil belajar yang didapatkan. Pada faktor eksternal, orang tua memberi peranan penting terhadap keberhasilan belajar siswa. Perhatian dan bimbingan orang tua akan membangkitkan motivasi dan minat belajar siswa sehingga hasil belajarnya sesuai dengan harapan.

\section{Metode Penelitian}

Penelitian ini menggunakan pendekatan kuantitatif dengan metode yang digunakan adalah eksperimen. Metode eksperimen merupakan cara ilmiah untuk mendapatkan data dengan cara memberi perlakuan terhadap kelas eksperimen. Desain yang digunakan adalah desain Quasi Experimental Nonequivalent Control Group Design. Karena dalam desain tersebut terdapat dua kelas penelitian yaitu kelas eksperimen (diberi perlakuan) berupa model pembelajaran bamboo dancing (tari bambu) dan kelas kontrol (tanpa perlakuan). Dengan demikian hasil perlakuan dapat diketahui lebih akurat, karena dapat membandingkan hasil belajar IPS siswa kelas eksperimen dan kelas kontrol.

Penerapan metode penelitian eksperimen dalam penelitian ini adalah tentang model pembelajaran bamboo dancing (tari bambu) terhadap hasil belajar. Kemudian data yang diperoleh dianalisis dan diolah sehingga dapat diketahui ada tidaknya pengaruh penggunaan model pembelajaran bamboo dancing (tari bambu) terhadap hasil belajar IPS siswa kelas V SD Negeri 1 Cipedes. 


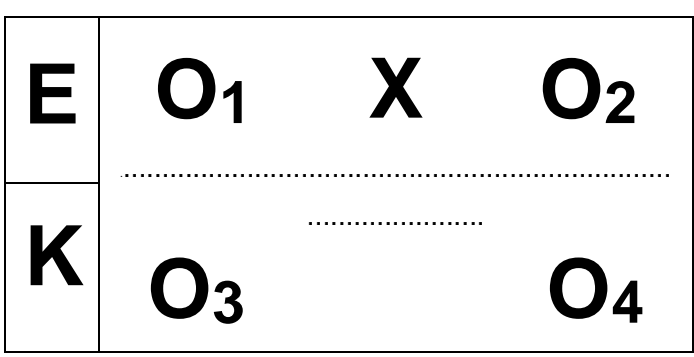

Gambar 1

Desain Penelitian Quasi Experimental Nonequivalent Control Group Design

(Sugiyono, 2016: 116)

Dalam penelitian ini sampel yang ditetapkan berjumlah dua kelas, yaitu kelas $\mathrm{V}$ eksperimen (diberi perlakuan) di SD Negeri 1 Cipedes berjumlah 35 orang yaitu laki-laki 20 dan perempuan 15 sedangkan kelas $\mathrm{V}$ kontrol (tanpa perlakuan) hanya sebagai pembanding, yaitu di SD Negeri 3 Cipedes berjumlah 13 orang yaitu laki-laki 3 dan perempuan 10 .

Teknik pengumpulan data yang dilakukan adalah tes, observasi, wawancara dan dokumentasi. Sedangkan instrumen penelitian yang digunakan adalah lembar tes, pedoman observasi dan pedoman wawancara.

Teknik analisis data terdiri dari uji instrumen penelitian (validitas tes, reabilitas, tingkat kesukaran,daya pembeda) dan uji statistik (uji normalitas, N-Gain, uji homogenitas, uji hipotesis)

\section{Hasil dan Pembahasan}

1. Hasil Belajar Kelas Eksperimen dan Kontrol (Pretest dan Posttest)

Hasil belajar IPS siswa kelas eksperimen dan kontrol (pretest dan posttest) terdapat perbedaan. Pada kelas eksperimen tahap pretest, nilai rata-rata hasil belajar siswa sebesar 53,49 dan pada kelas kontrol tahap pretest, nilai rata-rata hasil belajar siswa sebesar 50,15. Selisih hasil belajar pretest kedua kelas tersebut tidak berbeda secara signifikan, karena hasil pretest didapatkan tanpa adanya perlakuan.

Pada kelas eksperimen posttest, nilai rata-rata hasil belajar siswa sebesar 82,06 dan pada kelas kontrol posttest, nilai rata-rata hasil belajar siswa sebesar 71,69. Selisih hasil belajar posttest kedua kelas tersebut berbeda secara signifikan, karena kelas eksperimen diberi perlakuan berupa model pembelajaran bamboo dancing (tari bambu) dan kelas kontrol tanpa adanya perlakuan, melainkan hanya menggunakan metode konvensional atau ceramah.

Tabel 1

Rekapitulasi Hasil Belajar

\begin{tabular}{|c|c|c|l|}
\hline \multirow{2}{*}{ Kelas } & \multicolumn{2}{|c|}{$\begin{array}{r}\text { Rata-rata } \\
\text { hasil belajar }\end{array}$} & \multirow{2}{*}{ Kesimpulan } \\
\cline { 2 - 3 } & Kontrol & Eksperimen & \\
\hline Pretest & 50,15 & 53,49 & $\begin{array}{l}\text { Tidak } \\
\text { berbeda } \\
\text { secara } \\
\text { Signifikan }\end{array}$ \\
\hline Posttest & 71,69 & 82,06 & $\begin{array}{l}\text { Berbeda } \\
\text { secara } \\
\text { signifikan } \\
\text { Peningkatan }\end{array}$ \\
\hline
\end{tabular}

\section{Uji Hipotesis}

Uji hipotesis dilakukan untuk mengetahui pengaruh model pembelajaran bamboo dancing (tari bambu) terhadap hasil belajar IPS siswa kelas V. Diperoleh data hasil belajar pretest siswa kelas eksperimen sebesar 53,49 dengan varian 55,39 dan hasil belajar siswa kelas kontrol sebesar 50,15 dengan varian 71,15. Setelah itu dilakukan perhitungan dengan menggunakan 
uji-t polled varians, diperoleh nilai $\mathrm{t}$ hitung sebesar 1,44, kemudian dibandingkan dengan nilai $t$ tabel pada taraf signifikansi 5\% ( $\alpha=0,05)$ dan derajat kebebasan $(\mathrm{dk}=46)$ Kemudian diperoleh nilai $t$ tabel sebesar 1,67. Jika $\mathrm{t}$ hitung $<\mathrm{t}$ tabel $(1,44<1,67)$ maka $H_{0}$ diterima dan $\mathrm{H}_{1}$ ditolak atau tidak terdapat perbedaan hasil belajar IPS siswa kelas eksperimen dan kontrol pada tahap pretest.

Data hasil belajar posttest siswa kelas eksperimen sebesar 82,06 dengan varian 39,65 dan hasil belajar siswa kelas kontrol sebesar 36,39 dengan varian 71,69. Setelah itu dilakukan perhitungan dengan menggunakan uji-t polled varians, diperoleh nilai $t$ hitung sebesar 5,57, kemudian dibandingkan dengan nilai $t$ tabel pada taraf signifikansi $5 \%$ atau $(\alpha=0,05)$ dan derajat kebebasan $(\mathrm{dk}=46)$ Kemudian diperoleh nilai $\mathrm{t}$ tabel sebesar 1,67. Jika $t$ hitung $>t$ tabel $(5,57>1,67)$ maka $\mathrm{H}_{0}$ ditolak dan $\mathrm{H}_{1}$ diterima, artinya terdapat perbedaan hasil belajar IPS siswa kelas eksperimen yang diberi perlakuan dan kelas kontrol tanpa perlakuan atau hasil belajar IPS siswa kelas eksperimen lebih tinggi dibandingkan dengan hasil belajar IPS siswa kelas kontrol. Hasil perhitungan dituangkan pada tabel berikut:

Tabel 2

Rekapitulasi Hasil Uji Hipotesis

\begin{tabular}{|l|c|c|}
\hline \multicolumn{1}{|c|}{ Pretest } & $\begin{array}{c}\text { Kelas } \\
\text { Eksperimen }\end{array}$ & $\begin{array}{c}\text { Kelas } \\
\text { Kontrol }\end{array}$ \\
\hline $\begin{array}{l}\text { Jumlah Sampel } \\
(\mathrm{n})\end{array}$ & 35 & 13 \\
\hline Standar deviasi & 7,31 & 7,08 \\
\hline
\end{tabular}

\begin{tabular}{|l|c|c|}
$(\mathrm{S})$ & & \\
\hline Varian $\left(\mathrm{S}^{2}\right)$ & 55,39 & 71,15 \\
\hline Rata-rata $\overline{\mathrm{X}}$ & 53,49 & 50,15 \\
\hline thitung & \multicolumn{2}{|c|}{1,44} \\
\hline ttabel & \multicolumn{2}{|c|}{1,67} \\
\hline \hline Kesimpulan & $\begin{array}{l}\mathrm{H}_{1} \text { ditolak } \\
\mathrm{H}_{0} \text { diterima }\end{array}$ \\
\hline \hline \multicolumn{1}{|c|}{ Posttest } & $\begin{array}{c}\text { Kelas } \\
\text { Eksperimen }\end{array}$ & $\begin{array}{c}\text { Kelas } \\
\text { Kontrol }\end{array}$ \\
\hline $\begin{array}{l}\text { Jumlah Sampel } \\
(\mathrm{n})\end{array}$ & 35 & 13 \\
\hline $\begin{array}{l}\text { Standar deviasi } \\
(\mathrm{S})\end{array}$ & 9,05 & 8,46 \\
\hline Varian $\left(\mathrm{S}^{2}\right)$ & 39,65 & 36,39 \\
\hline Rata-rata $\overline{\mathrm{x}}$ & 82,06 & 71,69 \\
\hline $\mathrm{t}$ hitung & \multicolumn{2}{|c|}{5,57} \\
\hline $\mathrm{t}_{\text {tabel }}$ & \multicolumn{2}{|c|}{1,67} \\
\hline \hline Kesimpulan & \multicolumn{2}{|c|}{$\begin{array}{r}H_{1} \text { diterima } \\
\mathrm{H}_{0} \text { ditolak }\end{array}$} \\
\hline
\end{tabular}

3. Hasil belajar IPS sebelum menggunakan model pembelajaran bamboo dancing

Pada tahap pretest dikelas eksperimen penulis hanya memberikan tes kepada siswa kelas V SD Negeri 1 Cipedes. Hal ini bertujuan untuk membandingkan hasil belajar siswa kelas eksperimen dengan kelas kontrol SD Negeri 3 Cipedes atau kelas pembanding yang sama-sama tidak mengalami pembelajaran sebelumnya. Setelah dilakukan analisis, ternyata hasil belajar siswa kelas eksperimen pada tahap pretest dibawah rata-rata kriteria ketuntasan minimal (KKM) yang telah ditentukan yaitu 67 . Hasil belajar siswa pada tahap pretest kelas eksperimen diperoleh nilai ratarata sebesar 53,49 , nilai terendah sebesar 36 dan nilai tertinggi sebesar 64. Maka dapat disimpulkan bahwa, hasil belajar IPS siswa kelas V SD Negeri 1 Cipedes sebelum menggunakan model pembelajaran 
bamboo dancing (tari bambu) masih rendah atau dibawah kriteria ketuntasan minimal (KKM) yang telah ditentukan. Hal ini juga menunjukan bahwa tingkat pemahaman siswa terhadap materi pembelajaran masih kurang.

\section{Hasil belajar IPS setelah menggunakan model pembelajaran bamboo dancing}

Pada tahap posttest dikelas eksperimen SD Negeri 1 Cipedes, penulis menerapkan model pembelajaran bamboo dancing (tari bambu) pada saat pembelajaran. Sedangkan pada kelas kontrol penulis hanya menggunakan metode konvensional atau ceramah. Kelas eksperimen diberi perlakuan berupa model pembelajaran bamboo dancing (tari bambu) sedangkan kelas kontrol atau kelas pembanding tidak diberi perlakuan. Hal ini bertujuan agar dapat mengetahui perbandingan hasil belajar kedua kelas tersebut. Setelah dilakukan analisis, ternyata hasil belajar siswa kelas eksperimen pada tahap posttest diatas rata-rata kriteria ketuntasan minimal (KKM) yang telah ditentukan yaitu 67. Hasil belajar siswa pada tahap posttest kelas eksperimen diperoleh nilai rata-rata sebesar 82,06 , nilai terendah sebesar 72 dan nilai tertinggi sebesar 92. Hasil belajar IPS siswa kelas V SD Negeri 1 Cipedes setelah menggunakan model pembelajaran bamboo dancing (tari bambu) terdapat peningkatan atau diatas kriteria ketuntasan minimal (KKM) yang telah ditentukan dan rata-rata siswa memahami materi pembelajaran IPS tentang usahausaha persiapan kemerdekaan Indonesia. Berdasarkan deskripsi tersebut dapat disimpulkan bahwa model pembelajaran bamboo dancing (tari bambu) berpengaruh terhadap hasil belajar IPS siswa kelas V SD Negeri 1 Cipedes.

\section{Pengaruh model pembelajaran bamboo dancing terhadap hasil belajar IPS}

Berdasarkan hasil analisis data dan pengujian hipotesis mengenai pengaruh model pembelajaran bamboo dancing (tari bambu) terhadap hasil belajar IPS siswa kelas V SD Negeri 1 Cipedes, diperoleh nilai rata-rata posttest hasil belajar IPS siswa kelas eksperimen sebesar 82,06 lebih besar dibandingkan dengan nilai rata-rata posttest hasil belajar IPS kelas kontrol yaitu sebesar 71,69.

Hal tersebut dibuktikan melalui pengujian hipotesis statistik hasil belajar IPS siswa kelas eksperimen dan kelas kontrol pada tahap posttest yaitu diperoleh nilai thitung > ttabel $(5,57>$ 1,67), maka $\mathrm{H}_{1}$ diterima dan $\mathrm{H}_{0}$ ditolak dengan taraf signifikansi $5 \%$ atau $(\alpha=0,05)$ dan derajat kebebasan $(\mathrm{dk}=46)$. Artinya hasil belajar siswa kedua kelas tersebut berbeda, kelas eksperimen memperoleh nilai lebih tinggi dibandingkan dengan nilai hasil belajar kelas kontrol. Hal ini dikarenakan kelas eksperimen diberi perlakuan berupa model pembelajaran bamboo dancing (tari bambu).

Seperti yang dikemukakan oleh Huda dalam bukunya Cooperative 
Learning bahwa model pembelajaran bamboo dancing (tari bambu) dapat diterapkan dalam proses pembelajaran pada semua kelas dan pada semua mata pelajaran.

Huda (2011: 147), menjelaskan bahwa tari bambu merupakan pengembangan dan modifikasi dari teknik lingkaran kecil lingkaran besar. Selain itu, dinamakan tari bambu karena siswa diibaratkan seperti bambu yang berjajar serta saling berhadapan dan saling berbagi informasi pada waktu yang bersamaan dengan model yang mirip seperti dua potong bambu yang digunakan dalam tari bambu Filipina yang juga populer di beberapa daerah di Indonesia.

Model pembelajaran bamboo dancing (tari bambu) diterapkan pada proses pembelajaran karena memiliki keunggulan dibandingkan dengan metode konvensional atau ceramah. Huda (2011: 147), menjelaskan bahwa model pembelajaran bamboo dancing (tari bambu) memiliki keunggulan yaitu adanya struktural yang jelas, memungkinkan siswa untuk saling bertukar informasi dengan singkat dan teratur, memberi kesempatan kepada siswa untuk mengolah informasi dan meningkatkan keterampilan komunikasi mereka dan dapat diterapkan untuk semua kelas. Maka dari itu, dengan mengolah informasi dan keterampilan komunikasi tersebut siswa dapat memahami materi pembelajaran dan dapat meningkatkan hasil belajarnya.

Berdasarkan data hasil analisis, uji prasyarat, dan penelitian yang relevan diatas dapat disimpulkan bahwa model pembelajaran bamboo dancing (tari bambu) berpengaruh terhadap hasil belajar IPS siswa kelas V SD Negeri 1 Cipedes. Selain itu, model pembelajaran bamboo dancing (tari bambu) sangat penting diterapkan dalam proses pembelajaran khususnya pada mata pelajaran IImu Pengetahuan Sosial (IPS) agar siswa menjadi aktif, inovatif, dan kreatif. Setelah penulis terapkan pada penelitian ini, ternyata model pembelajaran bamboo dancing (tari bambu) dapat meningkatkan partisipasi siswa dalam proses pembelajaran, meningkatkan pemahaman materi terhadap siswa dan pada akhirnya memperbaiki hasil belajar IPS siswa kelas V SD Negeri 1 Cipedes yang semula dibawah kriteria ketuntasan minimal (KKM), kini mendapatkan nilai rata-rata hasil belajar diatas kriteria ketuntasan minimal (KKM) yang telah ditetapkan.

\section{E. Penutup}

\section{Simpulan}

Berdasarkan data hasil analisis dan pembahasan pengaruh model pembelajaran bamboo dancing (tari bambu) terhadap hasil belajar IPS siswa kelas V SD Negeri 1 Cipedes dapat disimpulkan bahwa terdapat pengaruh model pembelajaran bamboo dancing (tari bambu) terhadap hasil belajar IPS pada materi persiapan kemerdekaan Indonesia siswa kelas V SD Negeri 1 Cipedes. Hal ini dibuktikan melalui pengujian hipotesis statistik hasil belajar IPS siswa kelas eksperimen dan kelas kontrol pada tahap posttest 
yaitu diperoleh nilai thitung $>$ tabel $(5,57>$ 1,67), maka $H_{1}$ diterima dan $H_{0}$ ditolak dengan taraf signifikansi $5 \%$ atau $(\alpha=0,05)$ dan derajat kebebasan $(\mathrm{dk}=46)$. Artinya hasil belajar siswa kedua kelas tersebut berbeda, kelas eksperimen memperoleh nilai lebih tinggi dibandingkan dengan nilai hasil belajar kelas kontrol.

\section{Saran}

Penelitian ini diharapkan dapat memberi pengetahuan dan wawasan dalam melakukan penelitian selanjutnya dengan menggunakan model pembelajaran bamboo dancing (tari bambu) pada mata pelajaran Ilmu Pengetahuan Sosial.

\section{DAFTAR PUSTAKA}

Aqib, Zaenal. 2013. Model-model, Media dan Strategi Pembelajaran Kontekstual (Inovatif). Bandung : Yrama Widya.

Huda, Miftahul. 2011. Cooperative Learning. Yogyakarta: Pustaka Belajar.

Sapriya. 2009. Pendidikan IPS Konsep dan Pembelajaran. Bandung: PT Remaja Rosdakarya.

Shoimin, Aris. 2014. 68 Model Pembelajaran Inovatif dalam Kurikulum 2013. Yogyakarta: ArRuzz Media.

Sugiyono. 2016. Metode Penelitian Pendidikan. Bandung: Alfabeta.

Susanto, Ahmad. 2012. Teori Belajar dan Pembelajaran di Sekolah
Dasar. Jakarta: Prenadamedia Group. 